\title{
Spiral Antenna Design and Analysis As a Tool to Measure Partial Discharge in High Voltage Equipment
}

Deni Tri Laksono*, Dedi Tri Laksono, and Miftachul Ulum

Electrical Engineering Department, University of Trunojoyo Madura, 69162 Bangkalan, Indonesia

\begin{abstract}
The high-voltage equipment often experiences disturbances caused by the age of the equipment, installation errors, partial discharge disturbances. Of these kinds of disturbances, partial discharge is one of the most common disturbances in high-voltage equipment which has a percentage level of $80 \%$ due to partial disturbance. In this study, a research related to electrical equipment that can detect partial discharge disturbances in these high-voltage equipment was done. The equipment is a spiral antenna, where the spiral antenna has several advantages in detecting partial discharge. In making the first partial discharge, a literature study will be carried out first, after that designing a spiral antenna using CST 2018 software to get the Return loss and VSWR parameters as desired, namely Return Loss less than -10 and VSWR less than 2. From the results of this study Spiral antenna is measured using VNA, the measurement results show the spiral antenna is in accordance with the parameters that have been determined, namely the return loss value $=-30.8$ and the VSWR value $=$ between 1 to 1.5 .
\end{abstract}

Keywords: Partial Discharge, High-voltage, Disturbances

\section{Introduction}

Electricity in this era is a necessary to support human daily activities. The service of electricity must high quality. So to keep the quality of the electrical system, the quality of electricity must be very stable. The Industrial consumers want the electricity supply will continously and have quality so that industrial productivity is not disturbed.

This requires monitoring and electrical protection technology to be important aspects to maintant the system running properly. The substation is the part that distributes electricity from the power plant to the electrical load with various consumer loads. At substations, there are high voltage equipment will help distribute electricity to customers.

The high-voltage equipment are Transformers, GIS (Gas insulated switchgear) and other high-voltage equipment. It can suddenly disturb, so it must diagnose. Diagnosis is by using fault detection equipment without direct contact between technicians and high-voltage equipment, one way is to use a spiral antenna.[2] Because this type of antenna has several advantages over other types of antennas. Some of the advantages of spiral antennas are broadband (wide bandwidth) where this type of antenna can work at a frequency of $300 \mathrm{MHz}$ to $3 \mathrm{GHz}$, circular polarization, small size and high efficiency, and is suitable for online partial discharge measurements in high voltage equipment [2]. ][3][4].

\footnotetext{
* Corresponding author : deni.laksono@trunojoyojo.ac.id
}

In this research, a spiral antenna will made which is designed using CST software and with one-sided FR4 epoxy PCB material.

\section{Research Method}

The steps of this research show in the block diagram

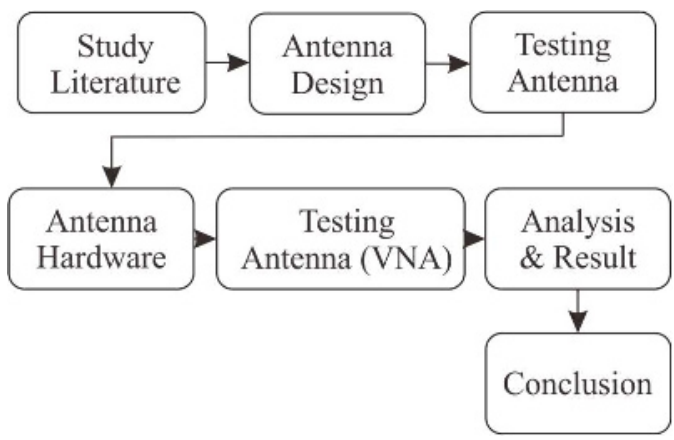

Fig. 1. Research method of this paper conference

\subsection{Literature Review}

\subsubsection{Partial Discharge}

That is a partial electrical discharge that event in the insulation it does not fully connected between two conductors and this discharge can occur, both near and 
far from the conductor, and this occurs an inhomogeneous field [2][5][6].

Basically partial discharge can occur in some place for example in the solid insulating materials, the liquid insulating materials and the gas insulating materials. In general, partial discharges are caused by local electrical concentration pressure, in the insulation that occurs inside or on the surface of the insulation itself.

The discharge process can be seen in Fig.2. under. The electrons first emerge from a protrusion of the conductor plate whose electric field is raised to a certain level.

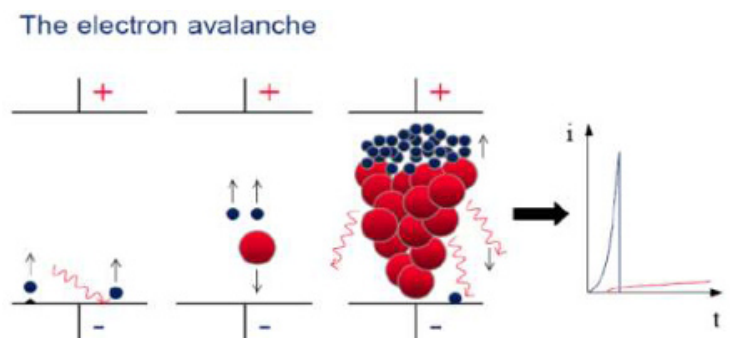

Fig.2. Mekanism of Partial Discharge[2]

There are 3 kinds of partial discharge sources, namely: Internal discharge, Surface discharge, and corona discharge.[8]

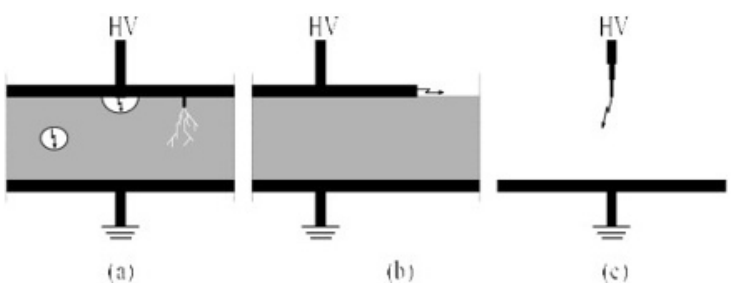

Fig.3. Source of partial discharge (a) Internal discharge (b) Surface discharge (c) Corona discharge [2].

\subsubsection{High Voltage Equipment}

Power Switchgear is equipment that is covered of metal. It design is completely enclosed all of sides using sheet metal materials, (except the ventilation openings and the inspection windows) which have the switching mains electrical circuit equipped with buses and connection equipment.

To get in to interior of the power switchgear which is covered by metal, a door of cover that can be opened flexibly has been provided to make it easier for technicians to carry out inspections and repairs [1].

\subsubsection{Antenna}

Antenna is a part of a telecommunications equipment system that can convert electromagnetic energy into electrical energy or vice versa that passes through a channel, both medium and vacuum.[3]

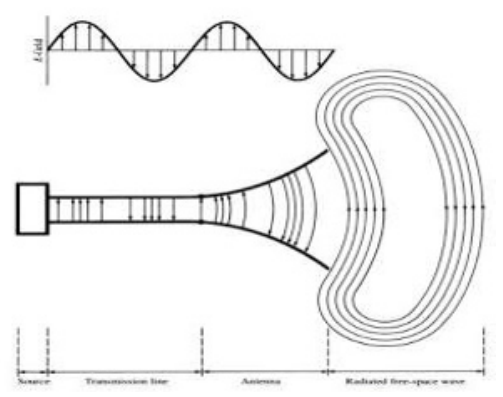

Fig.4. Concept of antenna level frequency[3]

\subsection{Spiral Antenna Design}

In this study, we design a spiral antenna with several advantages such as broadband, circular polarization, minimal size and high efficiency, and is suitable for online partial discharge measurements.

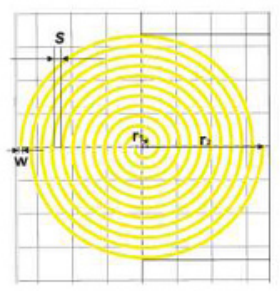

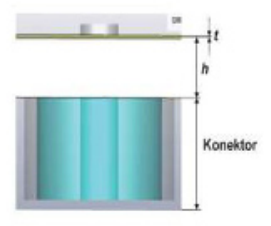

Fig.5. Design antenna spiral using CST software, (a) Tembaga pcb ; (b) Design konektor BNC.

\subsection{Manufacturing Spiral Antenna}

Spiral antenna is use to detect a partial discharge signal based on electromagnetic waves generated by the needle plate electrode.

The spesification of the spiral planar antenna is inner diameter spiral antenna $=1 \mathrm{~cm}$ and has an outer diameter $=13.8 \mathrm{~cm}$. Bellow show the manufakturing the antenna using FR4 PCB.

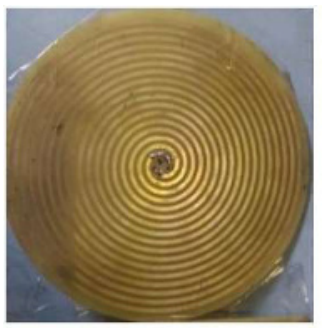

Fig.6. Manufacturing spiral antenna

\section{Result and Analysis}

\subsection{Measurement of Spiral Antenna Characteristics}

Measurement of antenna characteristics can be done using a Vector Network Analyzer (VNA) as shown in 
Figure 4.1, this tool can measure several antenna parameters like VSWR, Return Loss and antenna impedance.

Type of VNA used is VNA (TR1300/1), which provides basic vector network analysis for various industries and applications such as wireless communication, cable TV, automotive and others.

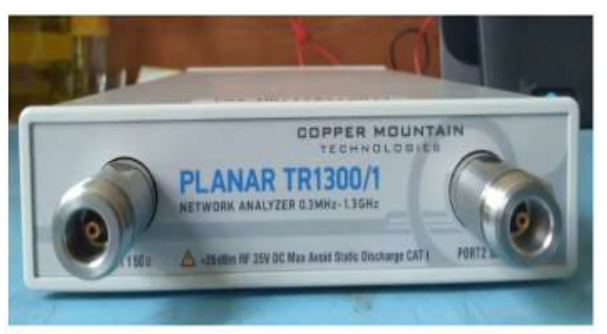

Fig.7. VNA ( TR1300/1)

\subsubsection{Result of measurement spiral antenna in Return Loss Parameters}

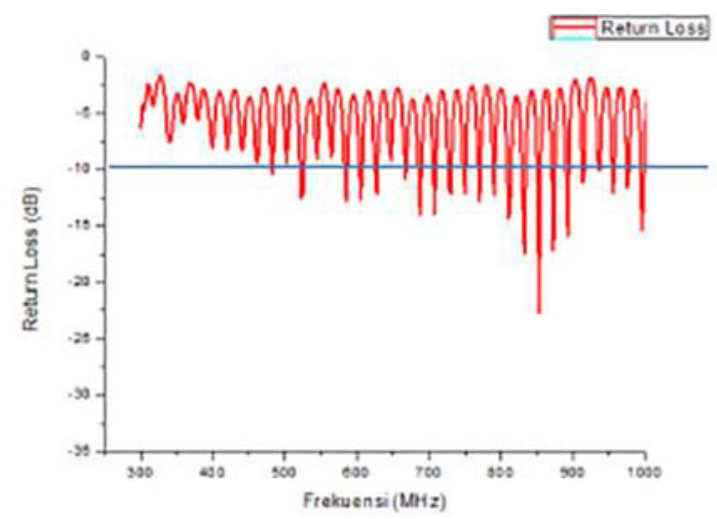

Fig.8. Rectangular spiral antenna RL curve

Table 1. Result of measurement Return Loss

\begin{tabular}{|c|c|c|c|}
\hline $\begin{array}{c}\text { Resonansi } \\
(\mathrm{MHz})\end{array}$ & $\begin{array}{c}\text { Bandwidth } \\
(\mathrm{MHz})\end{array}$ & $\begin{array}{c}\text { Frekuensi Optimum } \\
(\mathrm{MHz})\end{array}$ & $\begin{array}{c}\text { Return } \\
\text { Loss } \\
(\mathrm{dB})\end{array}$ \\
\hline $521-527$ & 6 & 524 & -13.313 \\
\hline $600-608$ & 8 & 604 & -22.47 \\
\hline $681-694$ & 13 & 687 & -22.313 \\
\hline $805-815$ & 10 & 810 & -20.476 \\
\hline $845-861$ & 16 & 852 & -28.329 \\
\hline $991-1000$ & 9 & 995 & -25.887 \\
\hline $1074-1079$ & 5 & 1077 & -17.903 \\
\hline $1117-1121$ & 4 & 1119 & -23.681 \\
\hline $1194-1200$ & 6 & 1199 & -30.857 \\
\hline $1236-1250$ & 14 & 1242 & -20.162 \\
\hline $1276-1291$ & 15 & 1284 & -18.757 \\
\hline
\end{tabular}

The method to read the bandwidth measurement results is in return loss parameters section which has a value is less than $-10 \mathrm{~dB}$, this value is an antenna parameter which states that the power lost from the signal is $<90 \%$. The data from the bandwidth measurement results on the tested spiral antenna can be seen in Table 1.

\subsubsection{Result of measurement spiral antenna in VSWR parameters}

The results of measuring the VSWR parameters using VNA on the spiral antenna.

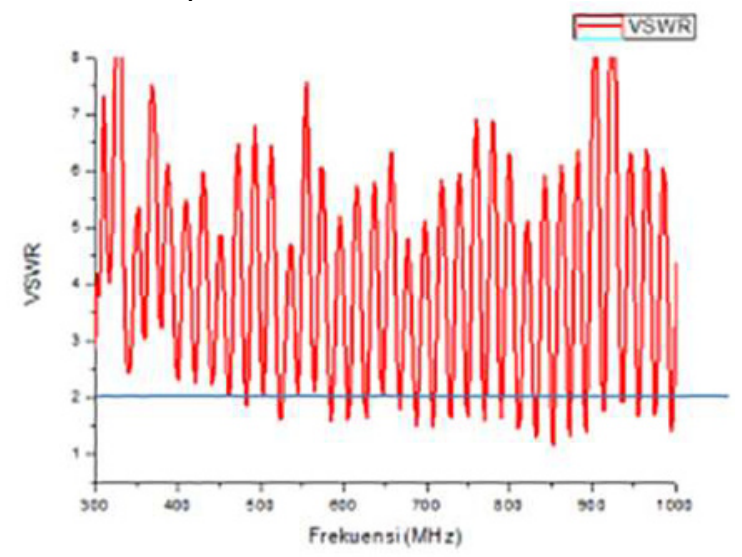

Fig.9. Graph of Rectangular spiral antenna VSWR

The results of the VSWR measurement on the antenna show a VSWR value is more than 1 and the best value is less than 2 . From this measurement can be know that antena can detect the signal from partial discharge.

\section{Conclusion}

This study discusses the design of a spiral antenna to detect partial discharge in high voltage equipment. The results of this research will show as follows:

1. The spiral antenna has made by FR4 PCB material.

2. The antenna designed using CST 2018 software with several parameters such as return loss, VSWR and $\mathrm{BW}$ (Bandwidth) values as a reference to produce an antenna according to the partial discharge frequency.

3. The results of antenna measurements using VNA show that the antenna is in accordance with the partial discharge signal measurement parameters, as evidenced by the Return Loss measurement of less than -10 and the VSWR value of less than 2 .

The acknowledgements: Thank you to Kementerian Keuangan Indonesia, LPDP (Lembaga Pengelola Dana Pendidikan), that give funding to this research.

\section{References}

1. B. Bridger, "Metal-Clad Switchgear or MetalEnclosed Switchgear: Which is it? Metal-Clad Switchgear or Metal-Enclosed Switchgear: Which is it?". Powell Industries, Inc, (1996).

2. Suwarno, "Diagnosis of High Voltage Equipments", Penerbit ITB, Bandung, (2010).

3. A. Balanis, "Antenna Theory Analysis and Design, Third Edition", Canada: A Jonh Wiley \& Sons, INC, (2005). 
4. D. T. Laksono and U. Khayam, "Comparison of peak to peak voltage and number of partial discharge detected by HFCT and loop antenna in metal enclosed high voltage equipment," 2017 International Conference on High Voltage Engineering and Power Systems (ICHVEPS), pp. 466-471,(2017).

doi: 10.1109/ICHVEPS.2017.8225891

5. Deni Tri Laksono et al, "10 Segment Spiral Antenna to Measure Partial Discharge on High Voltage Equipment “ IOP Conf. Ser.: Mater. Sci. Eng. 1125 012071, (2021).

6. Deni Tri Laksono et al," Comparison of Partial Discharge Characteristics Detected by RC Detector and Rectangular Antenna".J. Phys.: Conf. Ser. 1569 032086, (2020).

7. Dedi Tri Laksono et al, “ Comparative Measurement of Partial Discharge Using Spiral Antenna with RC Detector on High Voltage Equipment" (2020) J. Phys.: Conf. Ser. 1569032089

8. D. T. Laksono and U. Khayam, "Effect of the presence of metal box on partial discharge waveform and pattern detected by high frequency current transformer," 2017 International Conference on High Voltage Engineering and Power Systems (ICHVEPS), (2017), pp. 331-334, doi: 10.1109/ICHVEPS.2017.8225967.

9. F. Álvarez, F. Garnacho, A. Khamlichi and J. Ortego, "Classification of partial discharge sources by the characterization of the pulses waveform," 2016 IEEE International Conference on Dielectrics (ICD), (2016), pp. 514-519, doi: 10.1109/ICD.2016.7547655.

10. Suwarno, "Partial discharges in high voltage insulations: Mechanism, patterns and diagnosis," 2014 International Conference on Electrical Engineering and Computer Science (ICEECS), (2014), pp. 369-375, doi: 10.1109/ICEECS.2014.7045280.

11. Y. M. Hamdani and U. Khayam, "Application of Circular Patch Microstrip Antenna (CPMA) for Partial Discharge Detector in oil insulation," 2019 2nd International Conference on High Voltage Engineering and Power Systems (ICHVEPS), (2019), pp. 1-6, doi: 10.1109/ICHVEPS47643.2019.9011052.

12. Z. Zeng, Y. Hu and W. Zhang, "An External UHF Miniaturized Compound Spiral Slot Antenna for Partial Discharge Detection in GIS," 2020 8th International Conference on Condition Monitoring and Diagnosis (CMD), (2020), pp. 198-201, doi: 10.1109/CMD48350.2020.9287177.

13. J. P. Uwiringiyimana and U. Khayam, "Measurement of Partial Discharge in Air Insulation by using UHF Double Layer Bowtie Antenna with Modified Wings Edges," 2019 International Conference on Electrical Engineering and Informatics (ICEEI), (2019), pp. 228-233, doi: 10.1109/ICEEI47359.2019.8988866.

14. G. Robles et al., "On the use of Vivaldi antennas in the detection of partial discharges," 2013 IEEE
International Conference on Solid Dielectrics (ICSD), (2013), pp. 302-305, doi: 10.1109/ICSD.2013.6619887.

15. "IEEE Recommended Practice for Partial Discharge Measurements under AC Voltage with VHF/UHF Sensors during Routine Tests on Factory and Pre-Molded Joints of HVDC Extruded Cable Systems up to $800 \mathrm{kV}$," in IEEE Std 28622020 , vol., no., pp.1-31, 8 March (2021), doi: 10.1109/IEEESTD.2021.9374151. 